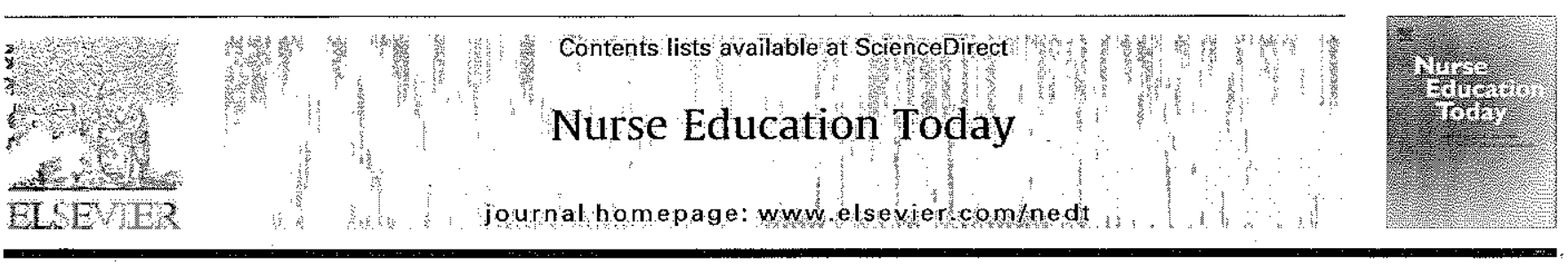

\title{
Mental health content of Australian pre-registration nursing curricula: Summary report and critical commentary th
}

\author{
Terence V. McCann ${ }^{\mathrm{a}, *}$, Lorna Moxham ${ }^{\mathrm{b}}$, Gerald Farrell ${ }^{\mathrm{c}}$, Kim Usher ${ }^{\mathrm{d}}$, Patrick Crookes ${ }^{\mathrm{e}}$ \\ a School of Nursing and Midwifery, Victoria University, PO Box 14428, Melboume, Victoria 8001, Australia \\ 'Central Queensland University, Rockhampton, Queensland, Australia \\ ${ }^{c}$ Division of Nursing and Midwifery, La Trobe University, Melbourne, Victoria, Australia \\ ${ }^{d}$ School of Nursing, Midwifery and Nutrition, James Cook University, Cairns, Queensiand, Australia \\ ${ }^{e}$ School of Nursing Midwifery and Indigenous Health, University of Wollongong, Wollongong, New South Wales, Australia
}

\section{A R T I C L E I N F O}

\section{Article history:}

Accepted 3 August 2009

\section{Keywords:}

Centralised clinical allocation

Core values

Mental health nursing content

Pre-registration nursing curricula

\begin{abstract}
S U M M A R
Background: Concerns have been expressed about inadequate mental health content in generic preregistration nursing curricula in Australia. These have led to claims new graduates are inadequately prepared to care for patients with mental health issues. The Mental Health Nurse Education Taskforce set up for the purpose of the project by the Australian Health Ministers' Advisory Council, carried out a national exploration of mental health content in pre-registration nursing curricula in order to develop a framework for including mental health in future pre-registration courses. This paper summarises the Taskforce's report, and presents a critical commentary on several aspects, of the Taskforce's report.

Methods: The project comprised a literature review, a national survey, national consultations, and advice from an Expert Reference Group.

Results: The report sets out a framework, which included the core values underpinning learning and teaching, learning outcomes, learning and teaching principles, and benchmarks for inclusion of mental health content in curricula. It recommended that a national approach needed to be taken to accreditation of curricula. This, together with greater collaboration between universities and clinical agencies, and the adoption of innovative strategies to secure clinical places, will help ensure a consistent adoption of the framework in each state and territory.
\end{abstract}

(c) 2009 Elsevier Ltd, All rights reserved

\section{Introduction}

Many countries are contemplating the most appropriate model of pre-registration nursing education to adopt, including Australia (Department of Education Science and Training, 2002; National Nursing and Nursing Education Taskforce, 2006) and the United Kingdom (UK) (Nursing and Midwifery Council, 2007; Robinson and Griffiths, 2007). Four models of pre-registration nursing education can be identified, ranging from specialist to generic (Robinson and Griffiths, 2007). First, direct entry specialist courses leading to a specialist qualification (e.g. Canada (western provinces), Ireland). Second, common foundation courses with special-

\footnotetext{
* The views expressed in this paper are those of the authors and not necessarily the opinions of the Mental Health Nurse Education Taskforce or the Australian Health Ministers' Advisory Council.

* Corresponding author. Address: School of Nursing and Midwifery, Victoria University, Po Box 14428, Melbourne, Victoria 8001, Australia. Tel.: +61 39919 2325; fax: +61399192832 .

E-mail addrësses: terence.mccann@vu.edu.au (T.V. McCann), l.moxham@cqu. edu.au (L. Moxham), g.farrell@latrobe.edu.au (G. Farrell), kim.usher@jcu.edu.au
} (K. Usher), pcrookes@uow.edu.au (P. Crookes). ist branches, leading to specialist qualification (e.g. UK). Third, generic courses with optional specialist components, leading to a generic qualification (e.g. only some in Australia). Fourth, generic courses with all students studying the same subjects, leading to a generic qualification (e.g. Australia, Canada (eastern provinces), and the USA). In Australia, the decision to transfer pre-registration nursing programs into higher education settings was ratified in 1984 , with the process completed during the 1990 s. At the same time, specialist curricula and registration were progressively replaced by generic curricula and registration (National Nursing and Nursing Education Taskforce, 2006; Usher, 2006).

There have been intermittent criticisms of generic curricula in Australia (Arnold et al., 2004; Happell et al., 2008a,b; McCann et al., 2009; Wynaden et al., 2000) and elsewhere (Cutcliffe and McKenna, 2006; Roxburgh et al., 2008; Younge and Boschma, 2006). In the UK, for instance, the decision to adopt common foundation curricula with specialist branches instead of generic courses was influenced by concerns about whether generic nurses would be fit for practice across the range of settings, such as mental health; fears generic nurses would be exploited by employers; and concerns about lack of professional development for generic 
nurses, especially in specialties like mental health, which would have detrimental effects on standards of care (United Kingdom Central Council for Nursing, 2001). From a mental health perspective in Australia, there are concerns about the adequacy of mental health content of pre-registration programs, with some calling for the reintroduction of direct entry programs (Stuhlmiller, 2005). Such criticisms have included failing to adequately prepare students to care for people with mental health problems, and contributing to the current shortage of nurses in the specialty (Australian Health Workforce Advisory Committee, 2003; National Nursing and Nursing Education Taskforce, 2006; Usher, 2006; Wynaden et al., 2000). Two key reports - the Scoping Study of the Australian Mental Health Nursing Workforce 1999 (Clinton, 2000; Clinton and Hazelton, 2000), and the National Review of Nursing Education 2002 - Our Duty of Care 2002 (Department of Education Science and Training, 2002) - highlighted the shortfalls of generic curricula in general. In relation to mental health content, they concluded universities had been unsuccessful in preparing students for beginning practice in mental health areas. The reports also noted how the quality of education was constrained by lack of good quality clinical placements in mental health settings, and by competition for those places available by nursing schools and students from other health professions. They recommended closer collaboration between health and university sectors to help overcome this problem for the future. Difficulties in obtaining clinical placements of appropriate quality also has been reported in other countries such as Canada, the UK and the USA (Moore, 2005).

In light of these and other criticisms, the Mental Health Nurse Education Taskforce (MHNET) was established to provide expert advice and make recommendations on the development of national policy and strategic directions for mental health nurse education, consistent with the National Mental Health Plan 2003-2008 (Australian Health Ministers, 2003). In 2008, the Taskforce conducted a national project, primarily to develop an agreed framework for embedding mental health content in pre-registration curricula. The aim of this paper is to outline the key components of the Taskforce's report into the mental health content of pre-registration courses. The objectives are to: (i) summarise the core values underpinning the learning and teaching mental health nursing. (ii) outline the principles for inclusion of mental health content in pre-registration nursing curricula, (iii) state the report's recommendations, and (iv) present a selective critical commentary of the report.

\section{Methods}

The project comprised four elements. First, a literature review was undertaken, specifically to update the literature since Clinton and Hazelton's (2000) scoping study of mental health nursing education conducted in Australia during 1999. Second, a survey of all universities providing pre-registration programs in Australia was carried out. A survey instrument was specifically developed by the Taskforce for the project. The instrument contained five sections, comprising 22 closed and five open response items: (a) biographical, (b) theory content, (c) clinical placements, (d) values and core principles of teaching and learning, and (e) innovation in clinical placements. The instrument was reviewed by a panel of experts comprising the Taskforce membership. A pilot study was carried out at two universities, following which minor amendments of the survey were made. The survey was distributed to all 35 nursing schools providing pre-registration courses in Australia. The response rate to the questionnaire was $77 \%$ ( 27 universities), with responses obtained from all states and territories. Third, national consultations took place with workshops being held in each state and territory with key stakeholders. The process entailed building an inclusive list of preferred values and principles, whereby previous workshop data was considered by the next group of participants. Nominal Group Technique (Delbecq et al., 1971) was used to encourage participants to identify key themes for discussion about curricula. In addition, consultation took place with state and territory nursing board representatives about the framework for mental health content of curricula, Fourth, an Expert Reference Group was established to give technical guidance to the project and ensure stakeholder participation. Membership included representatives from universities, government, mental health consumers (hereafter, consumers), carers, professional bodies, and registration and accreditation authorities. The Expert Reference Group met twice. At the first meeting, discussion took place about the literature review and survey findings, the draft core values and framework for mental health content in preregistration curricula. These were then discussed in workshops conducted throughout Australia. At the second meeting, the findings from the national consultations were considered.

\section{Report synopsis}

Based on information obtained from the literature review, survey, national-consultations, and Expert Reference Group comment, the MHNET recommended a framework for including mental health learning and teaching in pre-registration curricula that comprised the following elements:

- core values to inform teaching and learning;

- learning outcomes of mental health content;

- principles for teaching and learning mental health content; and

- benchmarks for inclusion of mental health content.

The MHNET also made recommendations which addressed barriers to implementing change in pre-registration curricula.

\section{Core values informing learning and teaching mental health nursing}

Three overarching themes informed the development of the core values and principles underpinning learning and teaching of mental health nursing: (a) mental health care is an essential foundation for all nurses, regardless of their field of practice; (b) diverse approaches should be adopted in mental health care, including health promotion, prevention, early intervention, illness management and recovery; and (c) an integral relationship exists between theory, evidence and practice. The 12 core values developed were intended to inform the mental health content of pre-registration courses (Table 1).

The core values need to underpin the students' learning outcomes, and are related to the Australian Nursing and Midwifery Council (Australian Nursing and Midwifery Council, 2005) competencies for registered nurses.

\section{Principles underpinning mental health in pre-registration nursing curricula}

Nine principles were recommended for guiding the inclusion of mental health content in curricula, relating to the personnel involved in teaching, university and mental health agency relationships, involvement in curriculum development, and pedagogical considerations (Table 2).

\section{Report recommendations}

Nine recommendations were made about incorporating mental health content in curricula. The recommendations ranged from 
Table 1

Core values informing the mental health content of pre-registration nursing curricula.

1. Consumers and carers have a right to participate in treatment and recovery processes

2. Mental health care involves advocating for consumers, challenging discrimination and working toward social inclusion

3. A therapeutic relationship is essential to treatment and recovery

4. A comprehiensive mental health assessment is a necessary foundation for treatment and recovery

5. Diverse approaches are needed to promote mental health, prevent and intervene in iliness and promote recovery

6. Mental tealth care takes account of the whole person, is empowering and positively focused on strengths and wellbeing

7. The safety and wellbeing of people with inental health issues and their carers is central to treatinent and recovery

8. A multi-disciplinary approach is used in treatment and recovery.

9. Mental health care is affected by social, political, economic and organisational influences

10. Mertal health inursing is a spectalty that provides complex intenventions to enfiance consumer and carer wellbeing

11. Mental health care requires ongoing engagement in critical reflection and a commitment to lifelong learning

12. Suitably qualified and experienced academic staff and clinicians as well as consumers and carers, make a critical contribution to mental health learning outcomes and teaching and learning:

Table 2

Principles for informing mental health content in pre-registration nursing curricula.

1. Theory and clibical practice should be taught at all times by people with specialist krowledge, skills and qualifications in mental health

2. Substantive partierships should exist between universities and clinical agencies to facilitate clinical placements, clinical teaching and scholarliness

3. Academic staff and cinicians with expertise in mental health, consumers and carees should be involved in the developnent, inplementation and evaluation of the mental health confent of curicula

4. A significant and incrementally hucreasing proportion of each year of curricula should be devoted to conpulsory mental health content and should be incoiporated in other appropriate subjects (e; acute care, aged care), and discretely assessed in increasingly complex ways in subsequent years of study

5. A minimum number of core clinical houtrs are recuited to achieve pre-règistration mental health outcomes

6. Course content should be evidence based and emplasise holistic care within a lifespan perspective, and challenge stigma

7. Equal value should be given to psychological and socíal care.

8. Students should have the opportunity to integrate mental health theory in diverse clinical settings

9. Core mental health related content should be included, for instance, consumer and carer participation: therapeutic relationships; and mental heâlth promotion

gaining support from strategic stakeholders to providing resources to enable intensive work to occur on curriculum development and implementation. First, the Commonwealth's Mental Health Workforce Advisory Committee (MHWAC) should seek support for implementing the mental health framework for curricula from key organisational and professional stakeholders. Second, state and territory accreditation authorities and, replacing these from 2010 onwards, the new national accreditation body, should incorporate the framework in course accreditation guidelines, and ensure experienced mental health academics, clinicians, consumers, carers and managers are included in the accreditation process. Third, MHWAC should encourage states and territories to develop a senior mental health nursing role that includes responsibility for strengthening mental health content in curricula and promoting collaboration between universities and health services. Fourth, targeted non-recurrent funding should be provided to assist universities to make more rapid change to curricula to ensure they comply with the recommended framework for mental health content. Fifth, the Commonwealth, states and territories should develop strategies to enhance the capacity of consumers and carers to participate in mental health curriculum development, delivery and evaluation. Sixth, the Commonwealth, states and territories should foster innovative approaches to securing mental health clinical placements. Seventh, MHWAC should seek funding for the establishment and maintenance of a 'clearing house' of teaching resources for mental health. Eighth, a range of scholarships should be provided to encourage mental health nurses to complete higher degrees in order to facilitate their transition to the mental health nurse academic workforce. Finally, responsibility for monitoring the implementation of the recommendations should be allocated to MHWAC.

\section{Discussion}

The MHNET report represents a first-step towards improving the mental health content of pre-registration curricula. The second and, arguably, greater step is to implement the key aspects of the report and ensure their sustainability. This discussion focuses on three key issues, crucial to successful implementation and sustainability: (i) the need to increase mental health content of curricula, (ii) the requirement to strengthen collaboration between universities and clinical agencies, and (iii) the necessity to adopt innovative approaches to generate clinical places.

\section{Increasing mental health content of curricula}

In most cases, it is important to achieve a sustainable increase in the proportion of mental health theory and clinical education of pre-registration nursing curricula to improve the practice readiness of graduates of generic courses (McCann et al., 2009; Mental Health Nurse Education Taskforce, 2008; National Nursing and Nursing Education Taskforce, 2006; Usher, 2006). While recommended that a sizeable and increasing proportion of each year of compulsory curricula should contain mental health theory and clinical practice, and mental health content should be incorporated in other nursing subjects, such as acute and aged care nursing. There are two possible perspectives to this position. On the one hand, the report can be criticised for failing to specify a minimum number of theoretical and clinical hours, unlike the UK's Nursing and Midwifery Council (Moore, 2005). This situation will only reinforce the present considerable disparity between and within states and territories about the amount of mental health content in curricula (Mental Health Nurse Education Taskforce, 2008). On the other hand, the report's authors wanted to avoid the idea that numbers of hours necessarily equate with students' learning and practice attainments. Instead, educational institutions are urged to concentrate on students' learning outcomes and move away from notions that theory and practice are necessarily separate activities, with separate locations thus reinforcing the metaphor of a theory-practice gap (Gallagher, 2004). A rigid concern over hours would likely exacerbate the difficulty some schools already experience in gaining quality clinical learning environments for their students (National Nursing and Nursing Education Taskforce, 2006), as well as reinforce the misperception that competency 
equates merely to hours spent in a clinical area. Institutions are encouraged to take a flexible and innovative approach to their learning, teaching and assessment activities. Regardless of these perspectives, it is essential to seek the support of the new national accreditation body to ensure the framework is adopted uniformly by all schools in the country. Integral to this process is the need to obtain the support of influential organisations and professional stakeholders, such as the Australia Nursing and Midwifery Council, Nursing and Midwifery Boards, the Australian College of Mental Health Nurses, and the Royal College of Nursing Australia (Mental Health Nurse Education Taskforce, 2008).

\section{Strengthening collaboration between universities and clinical agencies}

A key consideration in improving the amount and quality of teaching and learning of mental health is to develop stronger collaboration between universities and clinical agencies (Clinton, 2000; Clinton and Hazelton, 2000; Department of Education Science and Training, 2002; Mental Health Nurse Education Taskforce, 2008) (Box 1). This can be brought about by a range of measures, such as the introduction of joint appointments, reciprocal secondment of academic and clinical staff, and the establishment of clinical schools. From a mental health content perspective, there are three main benefits of stronger collaboration. It influences clinical staffs' willingness to support students through preceptorship (National Nursing and Nursing Education Taskforce, 2006; Usher, 2006; Wynaden et al., 2000). It also provides easier access to securing clinical placements (National Nursing and Nursing Education Taskforce, 2006). Finally, it strengthens the likelihood of students obtaining more relevant and up-to-date teaching of mental health theory and practice (Arnold et al., 2004; Wynaden et al., 2000). Although increased collaboration has benefits for all stakeholders, it carries additional costs to schools of nursing in areas such as liaison and provision of support to clinical agencies (National Nursing and Nursing Education Taskforce, 2006). Currently, these activities are not funded within the usual university model for funding nursing, in contrast to the funding received by medical schools.

Overall, while there are distinct benefits of stronger universityclinical agency collaboration, this strategy takes considerable time and resources to devejop, and needs to be built on trust and good communication (Arnold et al., 2004). Moreover, given the nature and geographical proximity of universities and clinical agencies, different models of collaboration may be necessary.

Strategies for strengthening university and clinical agency collaboration.

- Establish joint appointments

- Introduce reciprocal secondment of academic and clinical staff

- Establish clinical schools

- Take time to develop collaboration

- Commit adequate resources to building collaboration

- Build trust and maintain good communication

- Adopt an appropriate model of collaboration

\section{Adopting innovative approaches to generating clinical places}

A significant increase in demand for clinical places has taken place in recent years, and is projected to continue. This has occurred because of the increasing supply of pre-registration nursing and other health care professional students, in-response to the national shortage of personnel in these disciplines (National Health Workforce Taskforce, 2008). To illustrate, the number of commenc- ing nursing students has been increased from 8042 in 2002 to 13,895 in 2012 . It is estimated that by 2013 this will result in an increase in demand in excess of 613,750 clinical placement days per year (National Health Workforce Taskforce, 2008).

There are conflicting perspectives about the value of greater collaboration between universities and clinical agencies in obtaining clinical placements. On the one hand, collaboration increases schools' access to clinical placements, as a consequence of receiving preferential treatment from these agencies. On the other hand, schools with less collaboration may receive lower priority, or even be denied clinical places in those organisations (National Nursing and Nursing Education Taskforce, 2006). Moreover, irrespective of the level of collaboration, this initiative is unlikely to meet the increase in demand for clinical places. For instance, of the additional 500 Commonwealth Government nursing places offered to universities in 2008 , only 200 were taken up. One reason cited for the shortfall in up-take by Universities is the limited capacity of the health and education sectors to provide adequate clinical training places (National Health Workforce Taskforce, 2008).

Two additional initiatives have been proposed to help alleviate the shortfall in clinical placements. First, more flexibility in the timing and context of clinical placements has been recommended. For example, where not currently the case, clinical placements should be spread over the calendar year, instead of being concentrated mainly in discrete parts of the academic year (National Health Workforce Taskforce, 2008). More use could be made of the 24-h, 7-day week, and placements could be provided in a diverse range of contexts, including non-government agencies, notfor-profit organisations, and private and public settings (Mental Health Nurse Education Taskforce, 2008). Key to the implementation of these initiatives is greater openness and flexibility by schools, clinical agencies and course accreditation bodies (National Nursing and Nursing Education Taskforce, 2006).

Second, there may be a case for introducing a central clinical allocation agency in each state and territory. At present, placements are organised at the local level in schools (National Health Workforce Taskforce, 2008). While these systems may be advantageous to individual schools, they fail to address the broader issues of ensuring equitable access to, and cost effective use of, clinical placements. An alternative approach would be to use a central clinical allocation agency. It has been claimed that a central approach provides more equitable access to, and cost effective use of, clinical resources (British Columbia Academic Health Council (n.d.); National Nursing and Nursing Education Taskforce, 2006). The Canadian province of British Columbia's Health Sciences Placement Network (HSPnet) (British Columbia Academic Health Council (n.d.)) is an example of this type of system. This web based clinical allocation system, launched in 2003, coordinates all health sciences disciplines' clinical placements in the province. There are concerns, however, about the merits of a centralised clinical allocation system. It may undermine established collaborative arrangements (National Nursing and Nursing Education Taskforce, 2006), and may serve as a disincentive for schools to act proactively to establish joint partnerships with health care agencies to develop excellence and innovation in clinical education. Such a system is presently being introduced by the National Health Workforce Taskforce, as part of the solution to current and future workforce shortages.

\section{Conclusion}

The MHNET report seeks to do more than plug the gaps in generic pre-registration nursing courses. It sets out a progressive agenda for enhancing the mental health nursing content of programs. It promulgates the position that mental health theory and practice is 
an essential foundation for all nurses, irrespective of their domain of practice. At the same time, there is recognition of the specialised role and skills of mental health nurses. As well as updating core mental health content, emphasis is placed on adopting a broad range of approaches to mental health care, in addition to a primary focus on illness management and recovery. Prominence is given to the reciprocal relationship between theory, evidence and mental health practice, and emphasis is placed on consumer participation and the advocatory role of the nurse. Clearly, there are challenges ahead in implementing the report's agenda. Central to these are the need to seek the support of the new national accreditation body, strengthen collaboration between universities and clinical agencies, and to adopt innovative and flexible approaches to obtaining clinical placements. Finally, for other countries either using or debating the merits of adopting generic curricula, the critique provides some insight into the challenges around the mental health content of this particular model of pre-registration nursing education.

\section{Acknowledgement}

We acknowledge the contributions of the Mental Health Nurse Education Taskforce to this project, which was funded by the Australian Health Ministers' Advisory Council.

\section{References}

Arnold, S.A., Deans, C., Munday, J., 2004. University and service sector collaboration for undergraduate psychiatric nursing education. International Journal of Mental Health Nursing $13(1), 61-66$.

Australian Health Ministers, 2003. National Mental Health Plan 2003-2008. AGPS Canberra.

Australian Health Workforce Advisory Committee, 2003. Australian Mental Health Nurse Supply, Recruitment and Retention. AHWAC, Sydney.

Australian Nursing and Midwifery Council, 2005. National Competency Standards for the Registered Nurse. ANMC, Canberra.

British Columbia Academic Health Council (n,d.). Health Sciences Placement Network (HSPnet). <http://www.hspcanadanet/index.asp> (retrieved 13.01.09).

Clinton, M., 2000. Scoping Study of the Australian Mental Heaith Nursing Workforce 1999. Mental Health Branch of the Commonwealth Department of Health and Aged Care, Canberra.

Clinton, M., Hazelton, M., 2000. Scopíng mental health nursing education. Australian and New Zealand Journal of Mental Health Nursing 9, 2-10.

Cutcliffe, J.R., McKenna, H., 2006. Generic nurses: the nemesis of psychiatric/mental health nursing. In: Cutcliffe, J., Ward, M. (Eds.), Key Debates in Psychiatric Mental Health Nursing. Churchill Livingstone, Elsevier, London, pp. 92-106.

Delbecq, A.L., Van de Ven, A.H., Gustafson, D.H., 1971. Group Techniques for Program Planning: A Guide to Nominal Group and Delphi Processes. Scott, Foresman and Company, Glenview, Illinois.
Department of Education Science and Training, 2002. National Review of Nursing Education 2002 - Our Duty of Care. DEST, Canberra:

Gallagher, P., 2004. How the metaphor of a gap between theory and practice has influenced nursing education. Nurse Education Today 24, 263-268.

Happell, B., Robins, A, Gough, K., 2008a. Developing more positive attitudes towards mental hea!th nursing in undergradıate students: part 1 - does more theory help? Journal of Psychiatric and Mental Healtl Nursing 15 (6) 439-446.

Happell, B., Rosins, A., Gough, K., 2008b. Developing more positive attitudes towards mental health nursing in undergraduate students: part 2 - the impact of theory and clinical experience. Journal of Psychiatric and Mental Health Nursing 15 (7), 527-536.

McCann, T.V., Lu, S., Berryman. C, 2009. Mental health literacy of Australian Bachelor of Nursing students: a longitudinal study. Journal of Psychiatric and Mental Health Nursing 16, 61-67.

Mental Health Nurse Education Taskforce, 2008. Final Report: Mental Health in Preregistration Nursing Courses. Mental Health Workforce Advisory Committee, Melbourne. <http://www.nhwt.gov.au/mhwac.asp> (retrieved 06.01.09).

Moore, D., 2005. Assuring Fitness for Practice: A Policy Review. Nursing and Midwifery Council Task and Finish Group, London. <http://www.nmc-uk,org/ aDisplayDocument.aspx?documentrD=1251> (retrieved 15.06.09).

National Health Workforce Taskforce, 2008. Clinical placements across Australia: capturing data and understanding demand and capacity. <http://www.nhwt. gov.au/publications.asp > (retrieved 13.01.09).

National Nursing and Nursing Education Tasiforce, 2006. A report on Commonwealth funding to support the costs of clinical practicum for undergraduate nurses and midwives in Australia. <http://www.nnnet.gov.au/ downloads/rec24_clinical_practicum_reportpdf $>$ (retrieved 15.06.09).

National Nursing and Nursing Education Taskforce, 2006. A report on Commonwealth funding to support the costs of clinical practicum for undergraduate nurses and midwives in Australia. <http://www.nnnet.gov.au/ downloads/rec24 clinical_practicum_report.pdf $>$ (retrieved 18.05.08)

Nursing and Midwifery Council, 2007. The future of pre-registration nurse education. NMC, London. <http://www.nmc-uk.org/aArticle.aspx?ArticlelD= 2641> (retrieved 15.06.09).

Robinson, S., Griffiths, P., 2007. Approaches to specialist training at pre-registration level: an international comparison. National Nursing Research Unit, Kings College London, London. <http://www.kcl.ac.uk/schools/nursing/nnru/reviews/ specialist> (retrieved 12.06.09).

Roxburgh, M., Watson, R., Holland, K., Johnson, M., Lauder, W., Topping, K., 2008. A review of curriculum evaluation in United Kingdom nursing education. Nurse Eduction Today 28, 881-889.

StuhImiller, C., 2005. Rethinking mental health nursing education in Australia: a case for direct entry. International Journal of Mental Health Nursing 14 (3), 156-160.

United Kingdom Central Council for Nursing, M.a.H.V., 2001. Fitness for Practice and Purpose: The Report of the UKCC's Post Commission Development Group. UKCC, London. <http://www.nmc-uk.org/aDisplayDocument.aspx?documentID=629> (retrieved 15.06.09).

Usher, K., 2006. Nursing education in 2006. Journal of Advanced Nursing 3 (3), 219 220.

Wynaden, D., Orb, A., McGowan, S., Downie, J., 2000. Are universities preparing nurses to meet the challenges posed by the Australian mental health care system? Australian and New Zealand Journal of Mental Health Nursing 9 (3). 138-146.

Younge, O., Boschma, G., 2006. Debating the integration of psychiatric/mental health nursing in undergraduate nursing programs. In: Cutcliffe, J., Ward, M. (Eds.), Key Debates in Psychiatric/Mental Health Nursing. Churchill Livingstone, Elsevier, Philadelphia, pp. 107-119. 